\title{
Extrapyramidal features in advanced Down's syndrome: clinical evaluation and family history
}

\author{
P Vieregge, G Ziemens, M Freudenberg, A Piosinski, A Muysers, B Schulze
}

\begin{abstract}
Extrapyramidal, frontal release, and other neurological signs were studied in 54 demented and non-demented patients with Down's syndrome (DS). Fourteen patients were demented and five showed extrapyramidal signs, mainly of the rigid-hypokinetic spectrum and similar to Parkinsonian features in advanced Alzheimer's disease (AD). None of the non-demented patients had Parkinsonian signs. The mean age of the demented DS patients with extrapyramidal signs was significantly higher than that of the patients without. Frontal release signs were present in demented and nondemented patients. A questionnaire showed no increase in either the proportion of early- or senile-onset dementia or Parkinsonism among first- and seconddegree relatives of DS patients. Parkinsonian signs appear to be present at a lower frequency in DS than in advanced AD. A speculative hypothesis about a gene dosage effect of $\mathrm{Cu} / \mathrm{Zn}$-superoxide dismutase in preventing toxic radical formation in the substantia nigra of DS patients is presented.
\end{abstract}

A study of the effects of ageing on individuals with Down's syndrome (DS) may offer a particularly useful high-risk human model for Alzheimer's disease (AD). ${ }^{1}$ Several converging lines of evidence support a close association between $\mathrm{AD}$ and $\mathrm{DS}$. Neuropathological changes characteristic of $\mathrm{AD}$ (neurofibrillary tangles, senile plaques) are found in the brains of almost all DS individuals dying after the age of 35 years. ${ }^{2}$ Moreover, investigators have described age-related abnormalities in visual memory, ${ }^{3}$ adaptive and social behaviour, ${ }^{4}$ neurological status, ${ }^{5-8}$ EEG rhythms, ${ }^{9}$ and cerebral glucose metabolism ${ }^{10}$ in individual cases or series with DS patients, showing a subtle deterioration with advancing age and similar to the pattern found in AD. Mortality curves for DS individuals between 40-60 years appear remarkably similar to those for the general population between $60-80$ years. ${ }^{11}$

There are, however, discrepancies. Though "Alzheimer-type dementia" is present in some older DS patients, it does not occur with the same frequency as the plaques and tangles, nor is the degree of dementia predicted by the density of plaques and tangles. ${ }^{1}$ Furthermore, despite the morphological similarities the genetic relationship between $\mathrm{DS}$ and $\mathrm{AD}$ remains unclear. In relatives of index cases with $\mathrm{AD}$ a raised frequency for $\mathrm{DS}, \mathrm{AD}$, and haematological malignancies has been found, ${ }^{12-14}$ and an increased number of presenile dementia in relatives of DS probands was reported. ${ }^{15}$

There is growing evidence that patients with $\mathrm{AD}$ of early onset and familial occurrence may have a predisposing locus on chromosome 21 , while in families with senile onset such linkage could not be substantiated. ${ }^{1617}$

Patients with $\mathrm{AD}$ of an advanced stage exhibit extrapyramidal (EP) and particularly Parkinsonian signs to various degrees. ${ }^{18-27} \mathrm{~A}$ recent case control study provided evidence for a familial aggregation of AD with Parkinson's disease (PD). ${ }^{28}$ At necropsy, cell loss, neuromelanin deposition, Lewy body formation, and gliosis in the substantia nigra (SN) has been demonstrated in a proportion of $\mathrm{AD}$ brains. ${ }^{262930}$ Extrapyramidal signs in DS have until recently been referred to in one larger study $^{31}$ and in single cases. ${ }^{1032-34}$

To clarify the natural history of DS patients in middle and old age, we looked for EP system involvement and other neurological signs in DS patients and for evidence of familial clustering of $\mathrm{AD}$ and $\mathrm{PD}$ in families with an index case of DS.

\section{Patients and methods}

Fifty four patients ( 34 males, 20 females) with DS from various institutions were included in the study. The diagnosis of DS was established on the basis of the classic phenotype. Karyotype analysis was carried out wherever possible: 27 patients had "free" trisomy 21, two had a mosaic pattern, and one a translocation trisomy.

The history of each patient was taken. Special attention was given to diseases known to occur more frequently in DS, such as cardiac anomalies, myeloproliferative disorders, thyroid disease, previous neurological diseases and medication. The degree of characteristic phenotype of DS was assessed clinically. A neurological examination as detailed as possible in the individual patients was performed personally by one of us (PV). Fixed criteria were used according to the Unified Parkinson's Disease Rating Scale (UPDRS) $^{35}$ to evaluate the degree of hypokinesia, rigidity, resting tremor, postural abnormalities, walking pattern, and pulsion phenomena. Special attention was given to dyskinesias, myoclonic jerks, pyramidal signs 


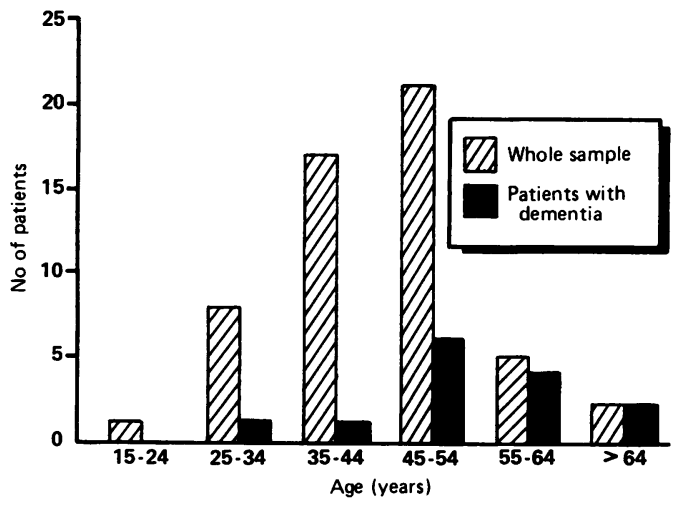

Figure Age distribution of 54 patients with Down's syndrome evaluated for extrapyramidal signs and dementia.

and signs of "frontal disinhibition" such as palmonental reflex (PMR), grasping reflex (GR), sucking and/or snouting reflex (SSR).

Dementia was clinically assessed by interview and/or by assessment of those caring for the patients using items about deterioration of personality, loss of initiative and conversation, self-help skills and cooperation, memory deficits, concentration, disorientation. Psychometric tests were not applied. Thirty five patients had EEG examination, nine patients cranial CT. A postal questionnaire on the occurrence of dementia and Parkinsonism in first- and second-degree relatives was obtained from the families of 38 patients.

Three patients (aged 17, 43, and 50 years) died within weeks or months of the clinical examination. At necropsy, both of the two older patients displayed typical brain morphology with atrophy of the superior temporal gyrus macroscopically and diffusely spread senile plaques and neurofibrillary tangles in the cortex microscopically.

\section{Results}

The age distribution of the whole patient sample is given in the figure. Table 1 shows the mean ages of the patient sample for dementia, extrapyramidal, and frontal signs. The mean age between female and male patients did not differ significantly. Fourteen DS patients (age range 27-67 years) were assessed to be demen-

Table 1 Number and mean (SEM) age of patients with Down's syndrome with dementia, extrapyramidal involvement, and signs of frontal disinhibition

\begin{tabular}{lll}
\hline Patient group & Number $(\%)$ & Mean age (years) \\
\hline Whole sample & 54 & $44 \cdot 4(9 \cdot 9)$ \\
Male patients & $34(63)$ & $44 \cdot 4(10 \cdot 0)$ \\
Female patients & $20(37)$ & $44 \cdot 9(10 \cdot 0)$ \\
Non-demented & $40(74)$ & $42 \cdot 2(8 \cdot 6)$ \\
Demented & $14(26)$ & $50 \cdot 9(10 \cdot 9)$ \\
Extrapyramidal & & \\
signs present & $5 / 14(36)$ & $59 \cdot 8(6 \cdot 7) \star \star$ \\
$\quad$ absent & $9 / 14(64)$ & $45 \cdot 8(9 \cdot 7)$ \\
PMR present & $30(56)$ & $48 \cdot 7(8 \cdot 1) \star \star \star$ \\
$\quad$ absent & $24(44)$ & $39 \cdot 0(9 \cdot 5)$ \\
GR present & $5(9)$ & $54 \cdot 2(11 \cdot 1)$ \\
absent & $49(91)$ & $43 \cdot 4(9 \cdot 4)$ \\
SSR present & $4(7)$ & $47 \cdot 3(3 \cdot 8)$ \\
$\quad$ absent & $50(93)$ & $44 \cdot 2(10 \cdot 2)$ \\
\end{tabular}

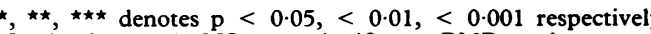
(Student's $t$-test); NS = not significant; PMR $=$ palmomental reflex; $G R=$ grasping reflex; $S S R=$ sucking and snouting reflex. ted. Their mean age was significantly higher than that of the 40 non-demented DS patients.

The mean age of five demented DS patients with extrapyramidal signs was significantly higher than that of the nine demented patients without extrapyramidal involvement. Signs of frontal disinhibition were present in demented as well as in non-demented DS patients. The mean age of patients with palmomental reflex and of those with grasping reflex was significantly higher than that of the patients without these signs. In the extrapyramidal involvement rigid-hypokinetic signs prevailed (table 2). Two further patients had oral dyskinesias, but were not included in the study as they were on current neuroleptic medication. Resting tremor and myoclonic jerks were not observed. No patient received levodopa treatment.

Other neurological signs unrelated to dementia were strabismus $(n=17)$, nystagmus $(\mathrm{n}=3)$, pyramidal signs $(\mathrm{n}=3)$, dysarthria $(n=1)$. Precocious ageing signs were: early grey hair $(n=5)$, cataract $(n=3)$, hypacousis $(\mathbf{n}=2)$. Grand-mal epilepsy was present in seven patients (two demented); two patients had occasional seizures. Seizures were observed a few weeks before death in one patient. Two patients were on anticonvulsant medication. EEG was normal in 11 patients, mildly abnormal in 13, and moderately abnormal in 11. None of the patients with seizures had epileptic discharges on the interictal EEG recording. There was no relation between severity of EEG changes and signs of frontal disinhibition or dementia.

Atrophic changes on CT were seen in two demented patients. Three non-demented patients had basal ganglia calcification, but no signs of extrapyramidal involvement.

No first-degree relatives with early-onset dementia (before 65 years) could be detected from the questionnaire. One mother had Parkinsonism before the age of 65 . Among 149 firstand second-degree relatives older than 65 years two had senile dementia (mother, paternal grandfather), and two had Parkinsonism (father, paternal grandfather). Other single neurological disorders in first-degree relatives were essential tremor, glioma, meningioma, epilepsy, and DS (a brother).

\section{Discussion}

Conclusions from our study should be drawn cautiously because of the methodological limitations in the clinical investigation of men-

Table 2 Extrapyramidal and "frontal" signs in 14 demented patients with Down's syndrome

\begin{tabular}{ll}
\hline Sign & $\begin{array}{l}\text { Number of } \\
\text { patients (\%) }\end{array}$ \\
\hline Rigidity & $3(21)$ \\
Shuffling gait & $4(29)$ \\
Hypokinesia & $3(21)$ \\
Hypomimia & $3(21)$ \\
Orofacial dyskinesia & $2(14)$ \\
Palmomental reflex & $9(64)$ \\
Grasping reflex & $3(21)$ \\
Sucking/snouting reflex & $2(14)$ \\
\hline
\end{tabular}


tally handicapped persons. In DS, nonspecific neurological signs can be observed at any age group. ${ }^{56}$ The frequency of frontal release and pyramidal signs, increased muscle tone, and hyperreflexia rises with advancing age..$^{5-836}$ In our investigation only the palmomental reflex was more frequently seen in the older patients. In contrast to the literature, other frontal release signs were less frequent and were also observed in non-demented DS patients. ${ }^{6-8} 31$

Since our investigation was cross-sectional and not prospective, it may have missed some neurological signs eventually occurring later in the course of advanced DS. This may explain the lower frequency of seizures and lack of epileptic discharges among the nonspecific EEG changes in our patient sample compared with other reports. ${ }^{78}$ Recent longitudinal studies have observed pre-terminal myoclonic jerks and seizures quite regularly in the course of advanced DS. ${ }^{31}{ }^{37}$ To a lesser degree such myoclonic and seizure activity is also found in advanced $\mathrm{AD} .^{24}$

No control group was used in this study because both the rate of development and the extent of extrapyramidal signs in DS was unknown and DS is a neurologically unique model of precocious ageing. We expected that the extrapyramidal system involvement might be encountered in DS patients with dementia, the latter most obvious on clinical presentation. Psychometric testing was therefore not applied. In this way the study confirmed that at a given stage of middle or old age only a certain percentage of DS patients are demented $(26 \%$ in our sample).

Extrapyramidal signs in older DS patients (36\% of demented; $9 \%$ of all) were more frequently seen than in other reports, where such signs were not mentioned or even absent. 56836 Lott et al refer to "gait deterioration" in $73 \%$ of their middle and oldaged patients late in the disease course. ${ }^{7}$ In a most recent investigation $20 \%$ of demented DS patients of middle and old age showed Parkinsonian signs. ${ }^{31}$ These different results may be due partly to the fact that the age group above 50 years is underrepresented in some studies. ${ }^{56}$ Our study was focused on EP signs and fixed criteria were used for EP evaluation.

Extrapyramidal signs in DS have up to now been described in single cases, for example, a 47 year old woman had choreiform movements and at necropsy had the morphological features of Pick's disease together with atypical $A D ;{ }^{33}$ a demented 63 year old DS patient had gait difficulties, rigidity, and nonspecified tremor. ${ }^{10}$ Postural tremor in advanced DS has been described in a patient by Jervis; ${ }^{32}$ a 23 year old male DS patient had developed resting tremor two years previously and showed masked face, cogwheel rigidity, generalised hypertonia, and the unsteady, festinant gait with reduced arm swing. ${ }^{34}$

Resting or postural tremor was not observed in our sample, but had been present in four out of $10 \mathrm{DS}$ patients with EP signs in another larger sample on dementia in DS. ${ }^{31}$ Two patients of that prospective investigation had Parkinsonism before the onset of dementia, whereas all of our DS patients with EP signs were demented. These patients were of a significantly higher age compared with those demented DS patients without EP involvement. It appears therefore from our study, that EP signs are features more likely to occur late in the clinical course of demented DS patients, but that such signs do not seem to be essential in the disease spectrum.

We found $36 \%$ of demented patients with EP signs in DS are in the range also found in AD patients. ${ }^{23-26}$ Others have described different percentages for their AD patients $\left(9 \% ; ;^{21}\right.$ $62 \% ; ;^{18} 65 \% ;^{27} 92 \%{ }^{22}$ ).

The main clinical feature in our study was of the hypokinetic rigid type. This bears similarities to Parkinsonism encountered during the course of AD. ${ }^{18-27}$ In our DS series none of the patients had tremor at rest, which in $\mathrm{AD}$ has been observed in between $4-48 \% .^{1820222527}$ Dyskinesias in $\mathrm{AD}$ unrelated to neuroleptic medication have been seen in $17 \%, 2223 \%,{ }^{20}$ and $38 \% .{ }^{25}$ In an unselected population of nondemented older people the rate was $38 \% .{ }^{38}$ In order to clarify, if dyskinesias in DS are more frequently present than $14 \%$ (our series), a prospective lifetime study of the individual patients seems necessary.

The occurrence of EP signs in AD can be sufficiently related to pathological changes in the substantia nigra (SN). ${ }^{262930}$ Also in DS, several neuropathological and neurochemical theories can support the clinical findings.

First, it is obvious from ours and from previous studies, that calcification of the basal ganglia, which is frequently encountered in DS, does not play a pathogenetic role in the development of EP features. ${ }^{39}$

The $\mathrm{SN}$ is less severely involved pathologically than other subcortical nuclei in young and middle aged DS patients, in contrast with AD. ${ }^{4041}$ On the other hand, the brains of patients with advanced DS show more numerous neurofibrillar tangles than comparable AD brains and mild to moderate $\mathrm{SN}$ pathology suggesting Parkinsonism (Lewy bodies, neuromelanin deposits). ${ }^{42}$ Others, however, did not observe Lewy bodies in older DS patients. ${ }^{43}$ Neurochemically the content of dopamine in the caudate nucleus and of homovanillic acid in the CSF is reduced in more advanced stages, while it is normal in young and middle aged DS patients. ${ }^{40445}$

Together, these findings support the finding that the pathological changes in the $\mathrm{SN}$ and the clinical presentation of Parkinsonism seem to be phenomena occurring late in the course of DS.

Why does the $\mathrm{SN}$ in DS seem to be afflicted so late in the disease compared with other regions of the brain and to a less severe degree than in $\mathrm{AD}$ ? One should remember that the triplication of the chromosomal segment $21 \mathrm{q} 22$ is responsible for an overexpression of the gene for the copper/zinc-superoxide dismutase $(\mathrm{Cu} /$ $\mathrm{Zn}-\mathrm{SOD})$. Such elevated gene dose may disturb the steady-state of active oxygen species within the cell, resulting in oxidative damage to biologically important molecules. It has been suggested that such a mechanism may in part 
be responsible for the mental retardation and for the $\mathrm{AD}$ pathology (that is, paired helical filament formation) associated with the DS phenotype. ${ }^{46}$

$\mathrm{Cu} / \mathrm{Zn}-\mathrm{SOD}$ on the other hand catalyses the conversion of superoxide radicals to hydrogen peroxide. In Parkinson's disease hydrogen peroxide and related oxygen radicals may be involved in the degeneration of dopamine neurons ${ }^{47}$ Cytosolic $\mathrm{Cu} / \mathrm{Zn}$-SOD-like activity and mitochondrial $\mathrm{Mn}$-SOD-like activity are increased in the $\mathrm{SN}$ of Parkinsonian brains at necropsy. ${ }^{48} 49$ In DS patients perhaps the excess of $\mathrm{Cu} / \mathrm{Zn}-\mathrm{SOD}$ serves as a protective mechanism in the $\mathrm{SN}$ by scavenging radicals occurring in nigral metabolism. This may result clinically in a Parkinsonian syndrome at a later stage and, possibly, to a lesser degree than expected from comparison with $\mathrm{AD}$. It has been also shown that $\mathrm{Cu} / \mathrm{Zn}-\mathrm{SOD}$ protects against toxic effects of pyridinium derivates (for example, paraquat), that are currently considered to play a pathogenetic role in Parkinsonism. ${ }^{50}$

It may also be possible that overexpression of $\mathrm{Cu} / \mathrm{Zn}-\mathrm{SOD}$ in familial, early-onset $\mathrm{AD}$ could result in Parkinsonian features at a lesser degree and, probably a later stage, when compared with those $\mathrm{AD}$ cases without linkage to chromosome 21 .

As mentioned earlier, there is a clinical and pathological overlap mainly in the late stages in $\mathrm{AD}$ and $\mathrm{PD}$. A recent family study reported an increased risk for $A D$ and for $P D$ among the relatives of probands with $\mathrm{AD}^{28}$ Previous pedigree analyses of index patients with $A D$ suggesting an increased risk in their relatives to suffer from $\mathrm{AD}, \mathrm{DS}$, and/or haematological malignancies have been criticised mainly on grounds of methodology and sample size..$^{1214}$ As a raised frequency of presenile dementia in relatives of DS patients has been reported, ${ }^{15}$ we undertook a similar, questionnaire-based inquiry on dementia and additionally on PD signs in the families of our DS patients. There was no increased rate of dementia with onset before the age of 65 years. Two senile-onset demented relatives among 149 persons at risk does not greatly exceed that expected from the age-specific prevalence rate for dementia over 65 years of age in the general population $(0.65 \%),{ }^{51}(2 \times 100): 149=1.34 \%$. The same applies for two relatives with senile-onset (after age 65 years) PD, given the similar age-specific prevalence rates for dementia in the seventh and eighth decade of life.

Thus our data do not provide better evidence of the relative risk of $A D$ and $P D$ in families with DS probands. This is mostly because the sample is small, the method was questionnairebased, and diagnostic proof of the cases at risk was not possible.

This investigation has shown that extrapyramidal signs may be a feature of advanced DS. They were encountered only in demented DS patients. This finding parallels Alzheimer's disease, where such signs may also occur in an advanced stage, but to a greater degree. To evaluate the extrapyramidal involvement in DS may help to clarify the debated association between $\mathrm{AD}$ and $\mathrm{PD}$, and further clinico- pathological and neuro-chemical studies in DS patients may be useful. Such studies may gain additional interest considering the role of free-radical formation and its prevention in the pathophysiology of idiopathic Parkinson's disease.

Historical information was kindly provided by the staff of the Kinderheim Vorwerk, Lübeck. We thank Dr A Kernbichler and Dr L Stappenbeck (Landeskrankenhaus Heiligenhafen), Dr J Mascher (Krankenhaus Rickling), Dr H Quadbeck (Rheinische Landesklinik-Psychiatrische Klinik der Universtät Düsseldorf), and $M$ Marterer (Karl-Bonhoeffer-Nervenklinik BerlinReinickendorf) for permission to investigate their patients. We thank Professor Dr K Lennert, former Head of the Institute of Pathology, Christian-Albrechts-Universität Kiel for transfer of necropsy data.

Wisniewski HM, Rabe A. Discrepancy between Alzheimertype neuropathology and dementia in persons with type neuropathology and dementia in persons with

Wisniewski KE, Wisniewski HM, Wen GY. Occurrence of neuropathological changes and dementia of Alzheimer's neuropathological changes and dementia of Alzheimer's
disease in Down's syndrome. Ann Neurol 1985;17:278-82.

3 Dalton AJ, Crapper DR, Schlotterer GR. Alzheimer's disease in Down's syndrome: Visual retention deficits. Cortex 1974;10:366-77.

4 Miniszek NA. Development of Alzheimer disease in Down's syndrome individuals. Amer J Ment Defic 1983;87: $377-85$.

5 Loesch-Mdzewska D. Some aspects of the neurology of Down's syndrome. J Ment Defic Res 1968;12:237-46.

6 Wisniewski KE, Howe J, Williams CG, Wisniewski HM. Precocious aging and dementia in patients with Down's Precocious aging and dementia in patients
syndrome. Biol Psychiatry 1978;13:619-27.

7 Lott IT, Lai F. Dementia in Down's syndrome: observations from a neurologic clinic. Appl Res Ment Retard 1982;3:233-9.

8 Wisniewski KE, Dalton AJ, Crapper McLachlan DR, Wen GY, Wisniewski HM. Alzheimer's disease in Down's syndrome: Clinico-pathologic studies. Neurology 1985; 35:957-61.

9 Veall RM. The prevalence of epilepsy among mongols related to age. JMent Defic Res 1974;18:99-106.

10 Shapiro MB, Haxby JV, Grady CL, et al. Decline in cerebral glucose utilisation and cognitive function with aging in Down's syndrome. J Neurol Neurosurg Psychiat 1987; 50:766-74.

11 Thase ME. Longevity and mortality in Down's syndrome. $J$ Ment Defic Res 1982;26:177-92.

12 Rocca WA. The etiology of Alzheimer's disease: epidemiologic contributions with emphasis on the genetic epidemiologic contributions with emphasis on the ge
hypothesis. J Neural Transm 1987;(suppl 24):3-12.

13 Huff FJ, Auerbach J, Chakravarti A, Boller F. Risk of dementia in relatives of patients with Alzheimer's disease. Neurology 1988;38:786-90.

14 Chandra V, Schoenberg BS. Inheritance of Alzheimer's disease: epidemiologic evidence. Neuroepidemiology 1989 8:165-74.

15 Yatham LN, McHale PA, Kinsella A. Down's syndrome and its association with Alzheimer's disease. Acta Psychiatr Scand 1988;77:38-41.

16 Schellenberg GD, Bird TD, Wijsman EM, et al. Absence of linkage of chromosome $21 \mathrm{q} 21$ markers to familial Alzheimer's disease. Science 1988;241:1507-10.

17 Goate AM, Haynes AR, Owen MJ, et al. Predisposing locus for Alzheimer's disease on chromosome 21. Lancet 1989; for Alzh

18 Pearce J. The extrapyramidal disorder of Alzheimer's disease. Eur Neurol 1974;12:94-103.

19 Drachman DA, Stahl S. Extrapyramidal dementia and levodopa. Lancet 1975;i:809.

20 Sulkava R. Alzheimer's disease and senile dementia of Alzheimer type. Acta Neurol Scand 1982;65:636-50.

21 Koller WC, Wilson RS, Glatt SL, Fox JH. Motor signs are infrequent in dementia of the Alzheimer type. Ann Neurol 1984;16:514-16.

22 Mölsä PK, Marttila RJ, Rinne UK. Extrapyramidal signs in Alzheimer's disease. Neurology 1984;34:1114-16.

23 Chui HC, Teng EL, Henderson VW, Moy AC. Clinical subtypes of dementia of the Alzheimer type. Neurology 1985;35:1544-50.

24 Mayeux R, Stern Y, Spanton S. Heterogeneity in dementia of the Alzheimer type: Evidence of subgroups. Neurology 1985;35:453-61.

25 Leverenz J, Sumi SM. Parkinson's disease in patients with Alzheimer's disease. Arch Neurol 1986;43:662-4

26 Morris JC, Drazner M, Fulling K, Grant EA, Goldring J. Clinical and pathological aspects of Parkinsonism in Alzheimer's disease. Arch Neurol 1989;46:651-7.

27 Tyrell PJ, Rossor MN. Extrapyramidal signs in dementia of Alzheimer type. Lancet 1989;ii:920.

28 Hofman A, Schulte W, Tanja TA, et al. History of dementia and Parkinson's disease in 1 st-degree relatives of patients with Alzheimer's disease. Neurology 1989;39:1589-92.

29 Ditter SM, Mirra SS. Neuropathologic and clinical features 
of Parkinson's disease in Alzheimer's disease patients. Neurology 1987;37:754-60.

30 Jellinger K. Neuropathological substrates of Alzheimer's disease and Parkinson's disease. J Neurol Transm 1987; (suppl 24):109-29.

31 Lai F, Williams RS. A prospective study of Alzheimer disease in Down syndrome. Arch Neurol 1989;46:849-53.

32 Jervis GA. Early senile dementia in mongoloid idiocy. $\mathrm{Am} \mathrm{J}$ Psychiat 1948;105:102-6.

33 Pogacar S, Rubio A. Morphological features of Pick's and atypical Alzheimer's disease in Down's syndrome. Acta Neuropathol (Berl) 1982:58:249-54.

34 Sturman SG, Williams AC. Parkinsonism and Down syndrome. Lancet 1989;ii:920-21.

35 Fahn S, Elton RL, and members of the UPDRS development committee. Unified Parkinson's disease rating scale. In: Fahn S, Marsden CD, Calne DB, Goldstein M, eds. Recent developments in Parkinsons disease, vol 2. Florham Park, NJ: Macmillan Health Care Information, 1987:153-67.

36 Owens D, Dawson JC, Losin S. Alzheimer's disease in Down's syndrome. Amer J Ment Defic 1971;75:606-12.

37 Reker M, Wolf P. Heterogeneity of Alzheimer's disease: the relevance of late-onset epilepsy in Down's syndrome as a
criterion for classification. J Neurol Transm (P-D Sect) criterion for

38 Delwaide PJ, Desseilles M. Spontaneous buccolinguofacial dyskinesia in the elderly. Acta Neurol Scand 1977;56: 256-62.

39 Wisniewski KE, French JH, Rosen JF, Kozlowski PB, Tenner M, Wisniewski HM. Basal ganglia calcification (BGC) in Down's syndrome (DS) - another manifestation of premature aging. Ann NY Acad Sci 1982;396:179-89.

40 Mann DMA, Yates PO, Marcyniuk B. Dopaminergic neurotransmitter systems in Alzheimer's disease and in Down's syndrome at middle age. J Neurol Neurosurg Psychiatry 1987;50:341-4.

41 Mann DMA, Yates PO, Marcyniuk B, Ravindra CR. Loss of neurons from cortical and subcortical areas in Down's syndrome patients at middle age. $J$ Neurol Sci 1987;80 79-89.

42 Gibb WRG, Mountioy CQ, Mann DMA, Lees AJ. The substantia nigra and ventral tegmental area in Alzheimer's disease and Down's syndrome. J Neurol Neurosurg Psychiatry 1989;52:193-200.

43 Leverenz J. Parkinson's disease in Alzheimer's disease and Down's syndrome. Neurology 1985;35(suppl 1):264-5.

44 Shapiro MB, Kay AI, May C, et al. Cerebrospinal fluid monoamines in Down's syndrome adults at different ages. monoamines in Down's syndrome
$J$ Ment Defic Res 1987:31:259-69.

45 Godridge H, Reynolds GP, Czudek C, Calcutt NA, Benton $M$. Alzheimer-like neurotransmitter deficits in adult Down's syndrome brain tissue. J Neurol Neurosurg Psychiatry 1987;50:775-8.

46 Zemlan FP, Thienhaus OJ, Bosman HB. Superoxide dismutase activity in Alzheimer's disease: possible mechanism for paired helical filament formation. Brain Res 1989;476:160-2.

47 Cohen G. The pathobiology of Parkinson's disease: Biochemical aspects of dopamine neuron senescence. J Neural Transm 1983;(suppl 19):89-103.

48 Marttila RJ, Lorentz H, Rinne UK. Oxygen toxicity protecting enzymes in Parkinson's disease. Increase of superting enzymes in Parkinson's disease. Increase of superoxide dismutase-like activity in the substantia
basal nucleus. $J$ Neurol $S c i$ 1988;86:321-31.

49 Saggu H, Cooksey J, Dexter D, et al. A selective increase in particulate superoxide dismutase activity in Parkinsonian substantia nigra. $J$ Neurochem 1989;53:692-7.

50 Epstein CJ, Avraham KB, Lovett M, et al. Transgenic mice with increased $\mathrm{Cu} / \mathrm{Zn}$-superoxide dismutase activity: animal model of dosage effects in Down's syndrome. Proc Natl Acad Sci USA 1987;84:8044-8.

51 Schoenberg BS, Kokmen E, Okazaki H. Alzheimer's disease and other dementing illnesses in a defined United States population: incidence rates and clinical features. $A n n$ Neurol 1987;22:724-9. 